\title{
Energia, um debate vital para o país
}

SERGIO LEITÃO



CARVÃO e o petróleo propiciaram o boom necessário para o funcionamento da sociedade industrial, responsável pela maior expansão da economia em toda a história. Em pleno século XXI, é o caso de perguntar se uma nova economia, baseada na sociedade do conhecimento, beberá da mesma fonte ou provocará uma revolução no campo da energia, que permita superar o legado das mudanças climáticas deixado pelos combustíveis fósseis. O debate sobre que combustível vai mover essa nova economia oferecerá pistas importantes para definir o modo como a sociedade vai funcionar nos próximos anos.

É preciso, por exemplo, descentralizar a produção de energia, aproveitando que as fontes limpas e renováveis estão em toda parte e ao alcance de todos. A nova economia, cujo valor está na produção do conhecimento e da informação, deverá funcionar com base em energias produzidas localmente, invertendo a lógica que até agora prevalece de que ao cidadão só é dado o direito de consumir, nunca o de produzir sua própria energia.

É fundamental trilhar outras veredas para tornar possível o sonho da revolução energética no Brasil. A primeira delas é popularizar a ideia de que todo e cada brasileiro pode produzir sua própria energia a partir do Sol que brilha generoso sobre nossas cabeças. É a exploração democrática desse "pré-Sol" muito menos oneroso que o pré-sal - que vai oferecer ao país a oportunidade de descentralizar sua produção energética, desmistificando a concepção dominante de que só teremos luz em nossas casas se construirmos grandes hidrelétricas e usinas nucleares.

O Brasil, como todas as nações que já alcançaram altos índices de desenvolvimento, precisará de mais energia, que desde a segunda metade do século XIX desempenha papel fundamental no funcionamento e fomento da sociedade industrial moderna. A energia é a responsável por movimentar inúmeros sistemas e equipamentos que, apenas no uso de motores elétricos, consomem aproximadamente dois terços de toda a eletricidade produzida no mundo.

Para que o país alcance sua autonomia energética é preciso considerar o extraordinário quadro de desafios em que se insere o debate sobre esse assunto nos dias de hoje. Ao lado das questões que já integravam o cenário tradicional de análise, como a guerra constante pelo controle dos estoques de petróleo e gás, o problema do aquecimento global e das mudanças climáticas lançou a mal- 
dição definitiva sobre o uso dos combustíveis fósseis na matriz energética. Esses precisam ser reduzidos progressivamente e depois abandonados, devido ao alto índice de emissões de gases de efeito estufa provenientes da sua utilização.

Será que estamos preparados para enfrentar esses desafios e evitar que mais uma vez se escolham caminhos tortuosos, que nos fazem chegar sempre atrasados ao futuro que outros países já alcançaram? Enquanto o mundo assiste a uma corrida tecnológica pela busca dos substitutos do petróleo, celebramos a descoberta do pré-sal como a redenção dos nossos pecados.

Preferimos investir R\$ 749 bilhões nos próximos dez anos no pré-sal a radicalizarmos e escolhermos a opção que começamos a escrever a partir da crise dos preços do petróleo na década de 1970, quando iniciamos o programa de substituição da gasolina pelo álcool.

Enquanto isso, por falta de uma política que incentive o uso de energias renováveis e limpas, está abandonado em nossos canaviais um potencial de geração de 28 mil megawatts, o equivalente a duas usinas Itaipu, segundo a União da Indústria de Cana de Açúcar (Unica). O país que poderia ser conhecido como a Civilização da Biomassa desperdiça a oportunidade de liderar a revolução tecnológica para o seu emprego em escala mundial como substituto dos combustíveis fósseis.

Ainda que o desmatamento consiga ser zerado até 2020, hoje a maior fonte de emissões de gases estufa do país, é provável que a emissão de 1,4 bilhão de toneladas de $\mathrm{CO}_{2}$ provenientes da exploração do pré-sal venha substituir essa fonte. Assim, as emissões nacionais - de 1,5 bilhão de toneladas por ano, de acordo com o inventário do Ministério de Ciência e Tecnologia (MCT) de 2004 - aumentariam exponencialmente. Este acréscimo deixará o Brasil entre os três maiores emissores de $\mathrm{CO}_{2}$ do mundo, atrás apenas de China e Estados Unidos.

Para responder a pergunta definitiva sobre se estamos preparados para alcançar a autonomia energética, de maneira ambientalmente correta e economicamente viável, é preciso saber como abastecer o aumento da demanda energética para um país obcecado pelo crescimento econômico. O que fazer com a limitação do potencial hidrelétrico na Amazônia em razão dos seus impactos socioambientais? O que fazer com a exploração do pré-sal por conta do aumento das emissões brasileiras dos gases de efeito estufa, bem como dos seus altos custos financeiros?

Pensar o futuro num país que perdeu por completo a capacidade de planejar o que quer ser em longo prazo não é tarefa fácil. Ainda mais quando esse planejamento implica abrir para a sociedade o debate sobre as opções de desenvolvimento que estão disponíveis, permitindo que as escolhas se façam de forma democrática, livre e plural.

Para tanto, é preciso dizer para a sociedade qual é o custo ambiental e econômico de cada opção, as implicações geopolíticas de cada decisão que tomamos ao privilegiarmos o uso de uma determinada fonte de energia, como a nuclear, 
por exemplo, em detrimento de outra. É justamente a análise sobre a energia nuclear que será o foco deste texto daqui por diante.

Ao falarmos de energia, estamos falando de desenvolvimento, do futuro que queremos construir para o país, para os nossos filhos e netos. Estamos discutindo se vamos alcançar o desenvolvimento revolucionando o modo como produzimos, com a incorporação de novas tecnologias, ou se vamos continuar utilizando antigos padrões e eternizar nossa dependência da exploração dos recursos naturais de que dispomos.

Nesse tema, a energia nuclear demanda enorme reflexão. É fundamental, por exemplo, analisar cuidadosamente os planos do governo de retomar a construção de usinas nucleares, anunciados ainda na gestão Lula e mantidos pela presidenta Dilma, mesmo com toda a repercussão em todo o mundo do acidente de Fukushima, no Japão, ocorrido em março de 2011.

\section{A retomada do Programa Nuclear Brasileiro}

A retomada do Programa Nuclear Brasileiro pelo presidente Lula, que estava paralisado desde o governo Collor, aconteceu quando o ministro de Assuntos Estratégicos, embaixador Samuel Pinheiro Guimarães, defendeu o uso da energia nuclear para resolver o problema das mudanças climáticas (Jornal Valor, 11.6.2010, Al4). Guimarães afirmou que ela seria "apta a gerar energia elétrica em grande escala, uma vez que boa parte dos problemas ambientais e de segurança estão superados". Vale lembrar que Fukushima reduziu a pó essa ilusão e a tornou risível diante dos severos olhos da história.

Infelizmente, a preocupação com o clima era apenas uma cortina de fumaça utilizada para camuflar a estratégia que o governo Lula montou para tornar o país uma potência atômica. ${ }^{1}$

A primeira etapa dessa estratégia se consolida com a contestação do Itamaraty à adesão do Brasil ao Protocolo Adicional do Tratado de Não Proliferação Nuclear (TNP), escorada justamente nas argumentações do embaixador Samuel Pinheiro, quando era secretário geral: "O Brasil não deve aceitar normas internacionais que contrariem ou criem empecilhos a seus interesses fundamentais de reduzir as desigualdades, de eliminar as vulnerabilidades e de realizar seu potencial... A reserva brasileira ou a ausência do Brasil de qualquer negociação não provocará nada de arrasador para o Brasil (como a recusa da Índia em aderir ao TNP demonstra cabalmente)...", publicado em Desafios brasileiros na Era dos Gigantes (Guimarães, 2006, p.297).

A segunda etapa aconteceu com a celebração de termos de cooperação, também durante o governo Lula, para transferência de material nuclear e conhecimento, com Rússia, Índia, China, França e Turquia, que permitiriam ao país estabelecer as bases de um fecundo mercado para exportar urânio, minério do qual, como afirmou o ex-ministro Samuel Pinheiro, possuímos uma das maiores jazidas do mundo.

A terceira etapa se relaciona com a reativação do Programa Nuclear Bra- 
sileiro, marcada pelo anúncio da construção da usina nuclear de Angra 3 e a intenção de construir outras usinas nucleares no Nordeste. Embora o argumento do governo seja de que essas usinas são para fornecer energia, o setor nuclear no Brasil opera como um complexo industrial-militar, onde suas partes integram a estratégia geral de domínio de uma tecnologia, independentemente de estarem nas mãos de civis ou militares.

O dinheiro empregado na construção das novas usinas nucleares estimulará o retorno de uma estrutura que estava paralisada desde o fim da ditadura nos anos 1980, começando pela formação de novos técnicos na área. Isso sem falar que a cada usina que construímos, aumentamos o volume de urânio a ser produzido, outro fardo com o qual teremos que lidar - a mineração de urânio traz riscos de contaminação do solo e da água, a exemplo das denúncias em relação à mina de Caetité, na Bahia.

Ainda há que considerar o uso da tecnologia nuclear para fins militares. A Estratégia Nacional de Defesa lançada pelo governo em 2008 afirma que "Projeto forte de defesa favorece projeto forte de desenvolvimento... Não é independente quem não tem o domínio das tecnologias sensíveis, tanto para a defesa como para o desenvolvimento". O problema é saber onde vamos parar. O começo já foi anunciado com a construção de submarinos movidos a propulsão nuclear. Embora a Constituição preveja que toda atividade nuclear será admitida somente para fins pacíficos, o assunto está longe de ser considerado intocável.

Nesse tema, nem enredo nem atores são novos. Ao final da ditadura, o Brasil tinha um programa nuclear paralelo que continuou a operar durante o governo Sarney. Antes, o programa ficava dividido entre os ministérios militares. Já no governo da chamada Nova República, ele foi abrigado no recém-criado Ministério da Ciência e Tecnologia (MCT), chefiado por Renato Archer.

Archer, em seu livro Energia atômica, soberania e desenvolvimento, conta que a "figura central da história do programa paralelo é o almirante Othon Luiz Pinheiro da Silva" (Rocha Filho; Garcia, 2006, p.155), atual presidente da Eletronuclear e responsável pela construção de Angra 3. Trabalharam com Archer no MCT o atual presidente do Banco Nacional de Desenvolvimento Econômico e Social (BNDES), Luciano Coutinho, o secretário executivo do Ministério e o atual ministro da Defesa, Celso Amorim, que foi secretário de Relações Internacionais.

Além disso, a estrutura do setor nuclear no Brasil também não é nova e foi mantida desde a ditadura, cabendo à Comissão Nacional de Energia Nuclear (CNEN) exercer o papel de fiscalizar e ao mesmo tempo fomentar o uso da energia nuclear. Isso contraria o Tratado que o país assinou que determina a separação dessas funções, deixando o Brasil na companhia do Irã e do Paquistão, únicos países onde isso ainda ocorre.

É preciso, tanto ou mais do que foi no passado, que o governo esclareça as reais intenções do seu programa nuclear, reconhecendo a relevância do controle 
das suas atividades, a ser exercido pelo Congresso Nacional, como determina a nossa Constituição. Só o debate democrático e livre, calcado em ampla informação, permitirá que a sociedade tome conhecimento dos problemas do uso da energia atômica.

\section{O desastre do césio-137}

\section{e a gestão do Programa Nuclear Brasileiro}

Ao falarmos de uma sociedade do conhecimento e plenamente informada, é relevante que essa possa ter conhecimento dos problemas que já aconteceram com a administração do Programa Nuclear no país, o que lhe permitirá avaliar não apenas seus defeitos e imperfeições, mas os riscos e perigos a que está submetida em decorrência disso. Assim, é fundamental resgatar das bibliotecas universitárias quatro trabalhos acadêmicos já defendidos, que traçam, por diferentes ângulos, um painel multifacetado do desastre do césio-137, ocorrido em Goiânia em 1987, o maior acidente radiológico urbano.

O desastre começou no dia 13 de setembro de 1987, quando dois catadores de Goiânia, curiosos com o brilho azul emitido pelo césio-137, recolheram o material encontrado nos escombros de um antigo hospital e o levaram para suas casas. Em pouco tempo o material radioativo, que estava dentro de um aparelho de radioterapia abandonado, se espalhou pela cidade e contaminou pessoas, animais e solo.

Após o desastre, foram recolhidos mais de 13,4 toneladas de lixo radioativo, armazenados posteriormente em um depósito construído na cidade de Abadia de Goiás (GO), distante 24 quilômetros de Goiânia. No entanto, a pior herança do césio foi a contaminação de mais de mil pessoas - os que sobreviveram até hoje sofrem com as consequências do acidente.

Os trabalhos acadêmicos são os seguintes:

De Elaine Campos Pereira, Riscos e vulnerabilidade socioambiental: o depósito definitivo de rejeitos radioativos na percepção dos moradores de Abadia de Goiás. Dissertação de mestrado apresentada ao Programa de Pós-Graduação em Sociologia da Faculdade de Ciências Humanas e Filosofia da Universidade Federal de Goiás;

De Suzana Helou (et al.), Césio-137 - Consequências psicossociais do acidente de Goiânia. Consolidação de várias pesquisas patrocinadas pela Universidade Federal de Goiás;

De Elza Guedes Chaves, Atos e omissões: acidente com o Césio-137 em Goiâ-nia. Tese de doutorado apresentada ao Departamento de Ciências Sociais do Instituto de Filosofia e Ciências Humanas da Universidade Estadual de Campinas; e

De Suzane de Alencar Vieira, O drama azul: narrativas sobre o sofrimento das vítimas do evento radiológico do césio-137. Dissertação de mestrado apresentada ao Departamento de Antropologia Social do Instituto de Filosofia e Ciências Humanas da Universidade Estadual de Campinas. 
Os trabalhos de Elza Guedes e de Suzane de Alencar reconstituem de forma detalhada o momento em que se foi solidificando, na população de Goiâ-nia e do país como um todo, a percepção de que havia uma falha gritante das autoridades da CNEN em exercer o controle sobre as chamadas fontes radioativas, principal razão do desastre do césio-137. Como foi revelado à época, o aparelho de radioterapia estava há mais de três anos abandonado, sem nenhuma fiscalização.

Vale resgatar o que diz Elza Guedes:

as peculiaridades do acidente em Goiânia mostraram que ele ocorreu porque o sistema de fiscalização falhou. A partir do momento em que a Comissão Nacional de Energia Nuclear foi identificada como uma das responsáveis pela fiscalização, o ceticismo contaminou as demais ações por ela empreendidas. Como sabemos, o emaranhado de leis e normas técnicas que regulavam as funções de fiscalização possibilitaram que legalmente a CNEN fosse inocentada desta responsabilidade. Entretanto, a percepção do público, apoiada em referência dos cientistas, não coincidiu com a decisão legal. Para boa parte da população, a CNEN deixou de cumprir, enquanto instituição, uma função de fiscalização que não se esgotava no ato de licenciamento da instituição para operar equipamentos radioativos.

Infelizmente, de lá para cá a situação não mudou muito. O Relatório do Grupo de Trabalho de Fiscalização e Segurança Nuclear, da Comissão de Meio Ambiente da Câmara dos Deputados, denunciou em 2007 que "o maior acidente radiológico do Brasil e do mundo aconteceu em Goiânia em 1987 devido a falta de controle de fontes radioativas no Brasil. Notamos que esta falta de controle permanece e estima-se que cerca de 1 mil fontes estejam sem controle no país".

\section{A gestão do Programa Nuclear no centro do palco}

Outro aspecto precioso dos trabalhos de Suzane de Alencar e Elza Guedes é jogar um facho de luz sobre o modus operandi da burocracia nuclear no Brasil, que, como dissemos antes, sempre manteve conexões com os militares, cultuando o segredo como a "alma do negócio". Ora, o desastre, em razão da sua repercussão, ainda que por um breve período, rompeu com tudo isso, obrigando o setor nuclear a se expor ao país.

Os gestores do Programa Nuclear, em primeiro lugar, procuraram afirmar sua competência exclusiva para lidar com o problema, afirmando que só eles estariam preparados para resolvê-lo, o que já servia como um escudo protetor contra qualquer interferência e crítica. A sociedade nada sabia sobre o assunto, portanto só lhe restava esperar pelas ações da estrutura de Estado apta a lidar com o problema.

Mas, em um segundo momento, quando as falhas não só em evitar a tragédia, mas também em lidar com suas consequências foram escancaradas pela mídia, o setor invocou o desconhecimento da população sobre a questão nuclear para lhe atirar a culpa de tudo o que estava acontecendo, eximindo-se de 
qualquer responsabilidade. Foi o que fez a CNEN em nota, citada na tese de Suzane de Alencar: "em Goiânia, houve um acidente radioativo provocado pela ignorância e pelo subdesenvolvimento (CNEN, 1987, p.133)".

Suzane ainda afirma que

o domínio do conhecimento formalizado e especializado em energia nuclear também pode ser aventado nos discursos para "inocentar" ou "redimir" os culpados. Ao mesmo tempo em que recai sobre a CNEN a responsabilidade sob o controle e registro das fontes radioativas no país, o órgão apresentou-se como a única instituição capaz de gerenciar a operação de descontaminação.

\section{A infalibilidade do setor nuclear e a construção de Angra 3}

Esse monopólio do saber atômico prevalece até hoje como uma das características centrais do setor no Brasil, que é sempre utilizado para conferir aos seus planos e projetos o dom da infalibilidade, afastando, de antemão, qualquer contestação por parte da sociedade.

Foi precisamente o que ocorreu com as dicussões sobre a retomada da construção da usina nuclear de Angra 3, em Angra dos Reis, no Estado do Rio de Janeiro. O setor não considerou os argumentos da sociedade civil contrários à construção, ou os da Academia e os do Congresso Nacional. Foi proclamada a segurança inquestionável da energia atômica, como sempre é proclamada até que venha o próximo acidente, e foi estabelecida uma ponte com o passado para resgatar um projeto ultrapassado, engavetado desde o final da ditadura.

É interessante registrar que, nas discussões sobre a construção de Angra 3, quando era trazido à tona o acidente de Chernobyl, ocorrido em 1986, o argumento da Eletronuclear era de que aquele acidente era fruto da decadência e da pobreza tecnológica da União Soviética e de que isso não se repetiria em países desenvolvidos. Novamente, culpa do subdesenvolvimento! A tragédia de Fukushima mostrou o equívoco desse tipo de argumentação, pois afinal o acidente aconteceu em um dos países mais organizados e desenvolvidos do mundo.

Até porque, Angra 3 é um poço de problemas e indefinições. A segurança da usina e de quem mora ao redor é preocupante. O projeto da parede que encapsulará seu reator é de apenas 60 centímetros, ao contrário da usina alemã que lhe serviu de modelo e tem o dobro da espessura. Quanto à população no entorno, em caso de acidente, ela estará entregue à própria sorte. Quase quatro décadas depois de inaugurado o Programa Nuclear Brasileiro, essas pessoas continuam sem rota de fuga definida para a eventualidade de vazamento de radiação.

A readequação do projeto a novas medidas de segurança pós-Fukushima acrescentaram outros R\$ 300 milhões ao valor total da obra, já estimado em mais de R\$ 10 bilhões de reais. Por conta dessas e de outras brechas no projeto de Angra 3, a Alemanha anunciou que não liberará a Garantia Hermes, fiança que garantiria $€ 1,3$ bilhão de bancos franceses para financiar a construção da Usina. Como esse dinheiro não veio, o governo Dilma, ao final de 2012 e de 
forma que passou quase despercebida, mandou a Caixa Econômica Federal bancar o empréstimo negado pelos europeus.

Por enquanto, Fukushima trouxe apenas duas lições para o Brasil: o país adiou por nove anos o investimento em novas usinas nucleares e o ministro Edson Lobão parou de dizer que tinha planos de ver 50 desses mamutes radioativos construídos aqui até 2050. É um alívio, porém pequeno.

\section{A insegurança é a regra permanente}

É justamente na parte relativa à segurança que o trabalho organizado por Suzana Helou, que trata das consequências psicossociais do desastre de Goiânia, traz elementos importantes para questionarmos o preparo do país, hoje, para lidar com acidentes nucleares. O que se viu após o acidente do césio foi um país inteiramente despreparado, sem contar, por exemplo, com equipes médicas treinadas para o acompanhamento especial que as vítimas requeriam, inclusive no aspecto psicológico, conforme é possível depreender da leitura do seguinte trecho: “desde a ocorência do acidente era notória a necessidade de um trabalho interdisciplinar por parte das equipes que davam atendimento aos radioacidentados, o que foi dificultado pela proporção do evento e pelo embaraço de lidar com o desconhecido".

Infelizmente, em Goiânia, esse despreparo não mudou nem mesmo com a criação da Fundação Leide das Neves Ferreira (FunLeide), órgão dedicado apenas a cuidar das vítimas do desastre. A Fundação foi justamente batizada com o nome da primeira pessoa morta pela contaminação radioativa, a menina Leide das Neves, que tinha apenas seis anos de idade.

O trabalho de Suzana atesta que os problemas de atendimento às vítimas continuaram, ao afirmar que

com a criação da FunLeide, era de se esperar que todas as equipes por ela incorporadas para a continuidade do acompanhamento aos radioacidentados trabalhassem multiprofissionalmente. Afinal, o estigma social e o comprometimento da saúde, inclusive das novas gerações de radioacidentados, exigiam da equipe responsável pela reabilitação um manejo dentro de um enfoque profissional integrador, que ia além da justaposição de diagnósticos e condutas. Tal expectativa, no entanto, nunca chegou a realizar-se de fato, salvo em algumas circunstâncias de crise.

O pior de tudo isso é que falta até o básico às vítimas do desastre do césio, não sendo raras as vezes em que o fornecimento de medicamentos é interrompido devido aos problemas orçamentários da FunLeide. Seria então o caso de perguntar qual a estrutura da qual dispõem os Estados de São Paulo e Rio de Janeiro para lidar com um acidente nuclear em Angra dos Reis, onde já estão situadas as usinas de Angra 1 e 2 e em construção a de Angra 3? Quais os hospitais habilitados para receber os contaminados? Quais as equipes médicas especialmente treinadas para lidar com o acidente?

Esse tipo de informação não está disponível para a sociedade brasileira e 
não sabemos se, em caso de um novo problema, não assistiremos novamente às cenas de despreparo que foram vistas em Goiânia em 1987. Apenas para relembrar, por falta de um Plano de Contingência para lidar com a situação, à época mais de 11 mil pessoas foram levadas para o Estádio Olímpico de Goiânia para serem monitoradas, em condições completamente inadequadas para o tratamento de casos de contaminação nuclear.

Em Angra dos Reis, não há nem a possibilidade de evacuar a população, pois a Rodovia Rio-Santos, principal via de ligação terrestre na região, vive constatemente bloqueda por queda de barreiras.

Como está dito no trabalho organizado por Suzana Helou, em "Goiás, especificamente, $\mathrm{o}$ acidente com o Césio-137 não foi suficiente para desencadear medidas preventivas por meio do fortalecimento da Defesa Civil e/ou de outras instituições de pesquisa, de educação e de prestação de socorros".

\section{O duplo ônus de ser vítima de um acidente nuclear}

Suzane Vieira, em sua tese, faz uma interessante discussão sobre o conceito de vítima em caso de acidentes nucleares, descrevendo o conflito com as autoridades do Programa Nuclear e do governo do Estado de Goiás, para que, no caso do césio-137, fossem consideradas como vitimados pelo desastre, por exemplo, pessoas que prestaram assistências às vítimas ou estavam diretamente envolvidas no trabalho de descontaminação dos bairros atingidos pela tragédia. Muitas pessoas só se descobriram como vítimas muitos anos mais tarde, sem falar nos casos em que se reproduzem os "distúrbios genéticos ao longo de gerações", criando os "filhos e netos do Césio", que tentam, por meio da Associação das Vítimas do Césio-137, obter do Estado tratamento médico.

O discurso técnico e científico empregado pela burocracia nuclear procura limitar a responsabilidade do Estado ao momento da contaminação radiológica, porque, para além da proteção a que sentem obrigados a dar ao governo por serem servidores públicos, procuram, em última instância, acreditar, para sua própria tranquilidade, que os efeitos do seu objeto de trabalho não possam acarretar tantos malefícios para a vida humana. Eles são programados para se autoiludirem.

É isso que dificulta, em todos os casos de acidentes nucleares, a precisão do número real de vítimas, oferecendo um álibi ao setor nuclear para diminuir suas responsabilidades e minimizar o tamanho dos seus impactos. Foi assim nos desatres das usinas nucleares de Chernobyl, na antiga União Soviética, e de Three Mile Island, ocorrido em 1979 nos Estados Unidos. E tem sido assim em Goiânia, com o césio-137.

O fato é que, se é verdade que as pessoas podem até não morrer imediatamente porque receberam pequenas doses de radioatividade, isso não significa que muitas não morrerão mais tarde devido ao contato com a radiação.

Esse é o traço comum que une o setor nuclear no mundo, que se defende na sotifiscação do seu aparato científico para engendrar a inimputabilidade dos 
seus erros, o que Ulrich Beck chama de Sistema de Irresponsabilidade Programada.

Já passou da hora de o Judiciário no Brasil e no mundo rever os parâmetros para julgar os casos de responsabilização dos danos causados por acidentes nucleares, evitando que as vítimas sofram duas vezes. A primeira, como vítimas que realmente são, com seus cânceres, seus tumores, "grávidos de morte", e a segunda, com a injustiça de não terem os seus direitos reconhecidos e a sua dor atenuada com um mínimo de assistência por parte do Estado.

Que a leitura dos trabalhos aqui descritos e a realização de novas pesquisas ajudem a sociedade a traçar contornos democráticos em torno do Programa Nuclear Brasileiro, que possam, como pediu o poeta Carlos Drummond de Andrade, afastar o caráter de ameaça que a construção de usinas nucleares representa. Como disse o poeta, se a ciência não pode garantir um nível de segurança que tranquilize o ser humano, nada justifica esse risco que será pago ao preço do "custo de vidas humanas".

Nota

1 Para o professor José Goldemberg, mesmo que fossem construídas três mil usinas nucleares no mundo nos próximos dez anos, hipótese inviável em razão do custo financeiro e ambiental, esse tipo de energia não serviria para minimizar os impactos das mudanças climáticas. Além do problema insolúvel do tratamento do lixo radioativo, ela emite mais gases de efeito estufa do que fontes limpas e renováveis como eólica, hídrica e solar. O kilowatt-hora gerado por uma usina atômica produz até 400 gramas de $\mathrm{CO}_{2}$ equivalente, enquanto um parque eólico produz no máximo 50 gramas.

\section{Referências}

ROCHA FILHO, A.; GARCIA, J. C. V. (Org.) Renato Archer-Energia atômica, soberania e desenvolvimento. Rio de Janeiro: Contraponto, 2006.

GUIMARÃES, S. P. Desafios brasileiros na era dos gigantes. Rio de Janeiro: Contraponto, 2006.

Sergio Leitão é advogado, diretor de Políticas Públicas do Greenpeace Brasil.

@ - sergio.leitao@greenpeace.org

Recebido em 22.1.2013 e aceito em 28.1.2013. 